\title{
GESTÃO EDUCACIONAL E A FORMAÇÃO DOCENTE NA CONSTRUÇÃO DA IDENTIDADE DOS PROFESSORES DE BEBÊS E DAS CRIANÇAS BEM PEQUENAS
}

\author{
EDUCATIONAL MANAGEMENT AND TEACHING TRAINING IN CONSTRUCTING \\ THE IDENTITY OF BABY AND VERY SMALL CHILDREN'S TEACHERS
}

\author{
Alini Imhof Dantas ${ }^{1}$ \\ Eliane Kormann ${ }^{2}$ \\ Joel Haroldo Baade ${ }^{3}$ \\ Recebido em: 30 nov. 2020. \\ Aceito em: 15 dez. 2020.
}

\section{RESUMO}

A atuação da gestão escolar requer a constante aprendizagem e um olhar empático voltado à coletividade. Este artigo apresenta uma discussão teórico-prática a partir do Estágio Supervisionado IV, tendo como objeto de pesquisa a gestão educacional. O objetivo do estudo foi refletir sobre o papel da Gestão Escolar na elaboração de uma proposta educativa democrática e participativa que promova e viabilize oportunidades para a formação docente continuada. A realização deste trabalho contou com um estudo teórico à luz dos estudiosos Darling-Hammond e Bransford (2019); Imbernón (2012) e Nóvoa (2019) que abordam a formação de professores; Lück (1997, 2009, 2014) e Libâneo $(2012,2015)$ que discutem a gestão escolar; Gonzalez-Mena e Eyer (2014) que debatem sobre um currículo de educação e cuidados baseado em relações qualificadas. A opção metodológica para subsidiar essa pesquisa se constitui numa abordagem qualitativa tomando a pesquisa-ação como perspectiva da investigação e transformação da realidade. Para tal, foi apresentado um plano de ação destinado às educadoras da Rede Municipal de Ensino de Brusque que atuam com bebês e crianças bem pequenas. As estratégias de formação utilizadas promoveram algumas ações, como: a interlocução entre teoria e prática por meio do estudo do tema "Apego"; registro escrito no diário de bordo; partilha das considerações no grupo de estudos; mobilização de reflexões sobre o papel da gestão na construção da identidade pessoal do professor; qualificação na relação com a especificidade do trabalho educativo do professor de bebês e crianças bem pequenas; compreensão da gestão sobre a proposta de formação permanente.

\footnotetext{
${ }^{1}$ Acadêmica do curso de Pedagogia da UNIFEBE. E-mail: alini.dantas@unifebe.edu.br.

2 Mestre em Educação. E-mail: eliane.kormann@unifebe.edu.br.

3 Doutor. Docente e pesquisador dos Programas de Pós-Graduação em Desenvolvimento e Sociedade e Profissional em Educação Básica da Universidade Alto Vale do Rio do Peixe - UNIARP. Coordenador do Núcleo de Educação a Distância do Centro Universitário de Brusque - UNIFEBE. E-mail: baadejoel@gmail.com.
} 
Palavras-chave: Gestão Escolar. Formação de Professores. Bebês. Crianças bem pequenas.

\begin{abstract}
The performance of school management requires constant learning and an empathic look towards the community. This article presents a theoretical-practical discussion based on Supervised Internship IV, with educational management as the object of research. The objective of the study was to reflect on the role of the School Manager in the elaboration of a democratic and participative educational proposal that promotes and enables opportunities for continuing teacher education. The realization of this work included a theoretical study in the light of the scholars Darling-Hammond and Bransford (2019); Imbernón (2012) and Nóvoa (2019) that address teacher training; Lück $(1997,2009,2014)$ and Libâneo $(2012,2015)$ who discuss school management; Gonzalez-Mena and Eyer (2014) who debate about an education and care curriculum based on qualified relationships. The methodological option to support this research is a qualitative approach taking action research as a perspective of investigation and transformation of reality. To this end, an action plan was presented to educators from the Municipal Education Network of Brusque who work with babies and very young children. The training strategies used promoted some actions, such as: the dialogue between theory and practice through the study of the theme "Attachment"; record written in the logbook; sharing of considerations in the study group; mobilization of reflections on the role of management in the construction of the teacher's personal identity; qualification in relation to the specificity of the educational work of the teacher of babies and very young children; management's understanding of the proposal for ongoing formation.
\end{abstract}

Keywords: School management. Teacher training. Babies. Very small children

\title{
1 INTRODUÇÃO
}

O Estágio Curricular obrigatório na Gestão Educacional compõe a matriz do curso de Pedagogia do Centro Universitário de Brusque - UNIFEBE e sugere articular a teoria à prática. A proposta metodológica passa por estudo da temática para construção do projeto do estágio, observação, vivências e desenvolvimento de propostas contemplando estratégias da Gestão Educacional, no que se refere ao processo de administração de recursos humanos, estrutura física, propostas pedagógicas, dentre outras.

O estágio nesse campo tem em seu projeto o objetivo de compreender o contexto da escola e o papel da Gestão Escolar na construção de uma proposta 
educativa democrática e participativa que promova e viabilize oportunidades para formação continuada dos professores.

Nesse contexto, a gestão tem a função fundamental de associar e gerir a função pedagógica e administrativa da Escola, papeis estes desempenhados pela direção e coordenação respectivamente. Libâneo (2015, p. 103) aponta que "a direção e coordenação são funções típicas dos profissionais que respondem por uma área ou setor da escola, tanto no âmbito administrativo quanto no âmbito pedagógico." A área da gestão escolar requer um conhecimento teórico da parte da administração dos recursos, mas também na pedagógica, dos processos de ensinar e aprender, esta última o sentido de ser da escola. Nesse sentido, essas dimensões auxiliam o profissional na sua prática a promover um olhar e ação equilibrados com o contexto da escola em que atua.

A atuação da gestão requer a constante aprendizagem, um olhar empático voltado à coletividade com o objetivo de acolher as diversas contribuições dos profissionais que atuam nas diferentes áreas da escola, assim como considerar o contexto das famílias e da comunidade escolar.

Nessa perspectiva, o Plano de Ação teve como proposta promover a formação continuada das professoras que atuam com bebês e crianças bem pequenas entre 6 meses e 2 anos e 8 meses de idade aproximadamente. $O$ objetivo foi criar momentos de estudo para oportunizar a pesquisa científica, a partilha de ideias e informações, o trabalho em grupo, o estudo e a reflexão, a socialização sobre a prática docente a fim de fomentar a formação permanente e a autoformação. Estas estratégias buscaram mobilizar a reflexão sobre a construção da identidade pessoal do professor e sua relação com a especificidade do trabalho educativo, neste campo com os bebês e crianças bem pequenas.

Cabe ressaltar que nesse semestre o estágio na Gestão ocorreu de forma atípica devido à pandemia causada pela COVID-19 e foi necessário refletir sobre um plano para atender aos professores nesse momento. Esse trabalho foi desenvolvido a partir da participação em uma de nossas aulas em take-home, via Google Meet, da gestora da creche, campo do estágio, Professora Orientadora do Estágio e acadêmica. A profissional da escola relatou algumas características da escola e da 
sua trajetória profissional. Os momentos seguintes ocorreram por meio de grupo de estudos tendo como meio de interação o WhatsApp, contato telefônico e recursos como Google drive e Google forms para a realização de questionário e disponibilização de material digital para a apresentação da proposta, orientações e materiais para estudo. $O$ desenvolvimento desse trabalho culminou na elaboração de um portfólio que documentou as interações do projeto.

A proposta foi uma sugestão para aprimorar a formação continuada docente e fomentar a autoformação dos professores no momento atual como um meio de viabilizar essa dinâmica diante desse cenário inusitado causado pela COVID-19, assim como uma sugestão de formação para o futuro, quando do retorno às aulas presenciais

\section{A GESTÃo ESCOLAR E SEU PERCURSO}

A educação tem um papel fundamental na transformação da vida das pessoas, tanto no aspecto pessoal quanto social. É na escola que a educação, em suas diversas dimensões, concretiza-se por meio do ensino, da aprendizagem, das relações humanas, dos valores que colaboram para um conhecimento que proporciona a melhoria de vida e diminuição das desigualdades. O Art. $1^{\circ}$. da Lei de Diretrizes e Bases da Educação Nacional estabelece "A educação abrange os processos formativos que se desenvolvem na vida familiar, na convivência humana, no trabalho, nas instituições de ensino e pesquisa, nos movimentos sociais e organizações da sociedade e nas manifestações culturais" (BRASIL, Art. $\left.1^{\circ}, 1996\right)$.

A mesma Lei 9394/96, quando trata dos princípios e fins da educação, tem a finalidade de promover "o desenvolvimento pleno do educando, sua preparação para o exercício da cidadania e sua qualificação para o trabalho" (BRASIL, Art. $\left.2^{\circ}, 1996\right)$.

Assim sendo, a escola é um lugar de construção do processo de desenvolvimento humano nos diversos aspectos, tendo em vista que a capacidade de atuar na sociedade depende do desenvolvimento de aprendizagens e conhecimentos sobre o mundo que são desenvolvidos no ambiente escolar (LÜCK, 2009).

Desde o período colonial até a Primeira República no início do século XX, há na educação a predominância de regras, normas a cumprir a fim de atingir um objetivo 
estabelecido. O período colonial apresentava a ausência de um sistema de ensino voltado à população e a educação não era prioridade daqueles que governavam. Entre 1920 e 1930, o Brasil passou por uma transformação política e cultural que promoveu o estudo profissional da administração educacional (SANDER, 2007). Ao longo desse período histórico o termo administração esteve presente nos pensamentos e fazeres da educação.

Aos poucos o termo gestão é incorporado ao pensamento da educação brasileira e vem, não para substituir, mas para trazer um novo olhar ao processo educativo. Esse conceito contemplado na Constituição Federal de 1988, avança quando vem acoplado à democracia em seu artigo 206, inciso VI, trazendo a "gestão democrática do ensino público, na forma da lei". A Lei de Diretrizes e Bases da Educação Nacional, n 9394/96 reforça a constituição e amplia, apontando que a gestão do ensino público deve ser democrática, respeitando a forma da lei e da legislação dos sistemas de ensino e, em seu artigo 14, traz a participação dos profissionais da educação e da comunidade escolar na elaboração do projeto pedagógico da escola (BRASIL, 1996).

Para Lück (1997), especialista em gestão escolar, o Gestor Educacional, na perspectiva da Gestão Democrática, tem alguns princípios que norteiam sua prática como a compreensão de que a evolução das organizações depende mais dos aspectos sociais, da cooperação, colaboração e competência do que insumos ou recursos. É necessário compreender a disposição dessa instituição como algo vivo e dinâmico, democratizando as relações e o projeto político pedagógico (LÜCK, 1997).

Cabe discutir ainda, os diferentes termos trazidos por estudiosos nas literaturas sobre quem dirige a escola ou instituição de ensino. Para Heloísa Lück, os termos administração e gestão se complementam, pois a administração faz parte da gestão escolar. "A ótica da gestão não prescinde nem elimina a ótica da administração educacional, apenas a supera, dando a ela um novo significado, mais abrangente e de caráter potencialmente transformador" (LÜCK, 1997, p.4).

Há também o uso do termo organização escolar que, segundo Libâneo (2012, p. 436), compreende abrangência na função da gestão: 
A organização escolar refere-se aos princípios e procedimentos relacionados à ação de planejar o trabalho da escola, racionalizar o uso de recursos (materiais, financeiros, intelectuais) e coordenar e avaliar o trabalho das pessoas, tendo em vista a consecução de objetivos.

Nesse sentido, as escolas são organizações em que as relações se dão para promover o desenvolvimento humano, a educação de pessoas, seus processos formativos pautados na democracia que torna possível a autonomia, liberdade de escolha e opinião, atuação e participação para tomar decisões no contexto escolar.

Ao considerar o processo de ensino - aprendizagem como atividade fim, fazse necessário refletir sobre a Base Nacional Comum Curricular (BNCC) e sobre como a gestão, na elaboração do seu Projeto Pedagógico, pode considerar e alinhar os preceitos estabelecidos neste documento que apresenta, normatiza e define um conjunto de aprendizagens essenciais que os alunos precisam desenvolver durante a Educação Básica, conduzido pelos princípios éticos, políticos e estéticos, tendo em vista a concepção de uma sociedade democrática e a formação humana integral (BRASIL, 2017).

Assim sendo, a gestão escolar, com o passar do tempo e acompanhando o contexto histórico de cada época, passou de uma posição que assumia um caráter administrativo apenas com a função de estabelecer e ditar regras a fim de atingir objetivos, para um serviço com o compromisso de desenvolver um trabalho que promovesse a participação ativa dos diferentes sujeitos da escola articulada com a comunidade.

Dessa forma, a gestão escolar reconhece e manifesta a consciência e ação de que está a serviço da sociedade em prol do bem comum e da constante busca de uma educação de qualidade para todos.

\subsection{Gestão escolar democrática}

A democracia se caracteriza por admitir os direitos e os deveres dos sujeitos para usufruírem e exercerem sua cidadania. Um conceito está atrelado ao outro e se constitui no próprio exercício da prática. "Direito e dever são conceitos que se desdobram e se transformam de forma contínua e recíproca pela própria prática democrática, que é participativa, aberta, flexível e criativa" (LÜCK, 2014, p. 70). 
A educação, portanto, é de responsabilidade da sociedade como um todo, e sua participação requer responsabilidade e posicionamento. Para que a escola desempenhe seu papel pedagógico e social é preciso que ela adote um perfil de gestão que possibilite a participação de todos os sujeitos que fazem parte do seu contexto: estudantes, professores, funcionários, pais, comunidade. "A gestão escolar, como área de atuação, constitui-se, pois, em um meio para a realização das finalidades, princípios, diretrizes e objetivos educacionais orientadores da promoção de ações educacionais com qualidade social" (LÜCK, 2009, p. 23).

A promoção de uma aprendizagem significativa que garanta 0 desenvolvimento e a cidadania de seus estudantes demanda a participação e a democracia na gestão escolar cujos princípios estão, também, apresentados na Lei de Diretrizes e Bases da Educação Nacional (Art. $3^{\circ}$. Inciso VIII), e na Constituição Federal (Art. 206, inciso VI).

A escola deve oferecer oportunidades de participação para que o aluno já tenha a experiência de exercer sua cidadania, consciente de seus direitos associados aos seus deveres, preparando-o para tomar decisões mediante reflexões críticas do que Ihe é apresentado, construindo dessa forma competências e habilidades necessárias para sua inserção e participação social. Um ambiente que promova a vivência democrática e crie condições para o desenvolvimento de competências e habilidades dos estudantes é condição para o exercício da gestão democrática (LÜCK, 2009).

É preciso considerar que o objetivo maior é promover o desenvolvimento e a formação do estudante para que ele se torne um cidadão atuante em sociedade. Nesse contexto, a ação conjunta de pessoas, ideias, ações é essencial para o desenvolvimento da função escolar.

Para que a escola assuma uma postura democrática em que a participação dos sujeitos envolvidos seja bem-vinda, ela precisa de ações estruturadas, permeadas pela legislação, mas que estejam em acordo com o contexto da escola "o sistema de ações é definido pelas políticas educacionais dos sistemas de ensino e pelo projeto pedagógico da escola" (LÜCK, 2014, p.65). 
Para propor e desenvolver suas ações a escola precisa construir seu Projeto Político Pedagógico, um documento fundamental que traduz intenções e concepções. O Art. 12 da Lei de Diretrizes e Bases da Educação Nacional, a LDB 9394/96, em seu inciso I estabelece que "os estabelecimentos de ensino, respeitadas as normas comuns e as do seu sistema de ensino, terão a incumbência de elaborar e executar sua proposta pedagógica".

O Projeto Pedagógico da escola necessita trazer implícito nos seus objetivos as concepções de equidade, qualidade e direito à educação, colaboração, já enunciadas na Base Nacional Comum Curricular "para além da garantia de acesso e permanência na escola, é necessário que sistemas, redes e escolas garantam um patamar comum de aprendizagens a todos os estudantes, tarefa para a qual a BNCC é instrumento fundamental" (BRASIL, 2017, p. 8).

Tanto a participação dos profissionais da escola quanto da comunidade escolar, possibilita conhecimento e compreensão do que está acontecendo nesse contexto, pois planejam e tomam decisões compartilhadas em direção aos objetivos comuns a serem alcançados. Os objetivos da organização precisam ser compartilhados por toda a comunidade escolar, dando liberdade para as pessoas agirem com criatividade (LÜCK, 2014).

A informação e compreensão do ambiente escolar podem estimular o comprometimento e a cooperação de todos os envolvidos em busca de uma educação de qualidade, por isso se dá a importância da participação em seus diferentes sentidos, segundo Libâneo (2015, p. 116) "participação significa a atuação dos profissionais da educação e dos usuários (alunos e pais) na gestão da escola. [...] Há a participação como meio de conquista da autonomia da escola [...] Há a participação como processo organizacional".

Além de compartilhar ideias e decisões, a gestão democrática participativa torna a escola um lugar aberto, em que as pessoas se sentem parte da realidade, e, para isso, deve abrir canais permanentes de comunicação com a comunidade que também educa e, assim, cria-se uma esfera de participação e responsabilidade pelas decisões, uma vivência de conviver em sociedade. "Por meio de canais de participação da comunidade, a escola deixa de ser uma redoma, um lugar fechado e 
separado da realidade, para conquistar o status de uma comunidade educativa que interage com a sociedade civil" (LIBÂNEO, 2015, p.116).

Ao mesmo tempo que discute e toma decisões, a escola pode apresentar-se como um espaço de formação para desenvolver autonomia diante da busca de conhecimento e formação dos envolvidos, um espaço de construção de competências para participar da vida em sociedade. "A escola é lugar de compartilhamento de valores e de aprender conhecimentos, desenvolver capacidades intelectuais, sociais, afetivas, éticas, estéticas. Lugar de formação de competências para a participação na vida social econômica e cultural" (LIBÂNEO, 2015, p. 116).

Este lugar, chamado escola, é o espaço onde o aprender está associado ao fazer, ou seja, é durante o caminho de trabalho pautado no esforço, liberdade com responsabilidade, comprometimento, colaboração, diálogo que as pessoas aprendem e constituem sua formação, considerando que "a gestão democrática constitui-se em instrumento de luta em defesa da horizontalização das relações, de vivência e convivência colegiada, superando o autoritarismo no planejamento e na organização curricular" (BRASIL, 2013, p. 56). Assim, a gestão democrática procura conduzir e harmonizar os procedimentos administrativos e pedagógicos da escola.

É fundamental que as relações humanas sejam aprimoradas e valorizadas por meio do diálogo e da escuta, assim como da delegação de responsabilidades para que, por meio da gestão democrática, a educação de todos e para todos transcenda o prescrito no papel.

\section{2 papel da gestão escolar}

Considerando que a escola é uma comunidade em que valores, ensino e aprendizagem são compartilhados, há a necessidade de um líder com características que possam contribuir para o desenvolvimento de forma harmônica desse espaço nas suas variadas dimensões. Conforme Lück (2014), a liderança nos espaços escolares diz respeito a um conjunto de ações, atitudes e comportamentos que uma pessoa apresenta para influir o desempenho de outras pessoas, visando à realização de objetivos educacionais. 
Algumas características do líder democrático são relevantes, tais como: empatia, escuta, diálogo, humildade, generosidade, disposição, resiliência e contribuem para o revigoramento da escola como um todo. "O líder democrático atua, portanto, orientado pelos princípios da perspicácia e abertura em relação a todos os momentos e ambientes educacionais da escola, como oportunidades para a ação conjunta no sentido de maior desenvolvimento" (LÜCK, 2014, p. 79).

A liderança não se caracteriza pelo exercício do poder, mas pela pessoa que que vai à frente da sua equipe abrindo caminhos e apresentando possibilidades de um trabalho a ser realizado em cooperação, bem como partilha de ideias aliadas a ações a fim de contribuir para o avanço da escola e dos sujeitos que a formam.

Outras características da gestão são apontadas por Libâneo (2015), autoridade, mesmo que sirva para exercer sua função é aconselhável que seja descentralizada; responsabilidade que é inerente ao cargo do gestor apesar de a descentralização das decisões; disciplina na conciliação das suas atividades às normas; decisão para resolver situações mesmo tendo a participação da sua equipe; iniciativa para enfrentar circunstâncias inesperadas.

A gestão precisa ter a visão de todos os campos que constituem a escola, articulando-os, tendo atividades predominantes na área da gestão administrativa, mas que se revela no campo pedagógico, da sala de aula, já que se trata de um projeto educacional, e este, tem como principal objetivo o processo de aprendizagem. Libâneo (2015) afirma que a direção tem funções predominantemente gestoras e administrativas, no entanto, elas têm uma implicação pedagógica, pois existe na dependência do campo educativo.

Cabe ressaltar que, ao lado da função da direção está a coordenação pedagógica, que o auxilia na gestão, mas que tem funções específicas de atuação. A assistência pedagógica aos professores, é uma das principais incumbências da coordenação, que deve auxiliar a viabilizar, integrar e articular contextos de aprendizagem adequados aos estudantes (LIBÂNEO, 2015).

Apesar de distintas e responsáveis por aspectos diferentes, ambas as funções caminham lado a lado. Tanto a direção como a coordenação pedagógica demandam uma postura interativa para desempenhar um trabalho que considere a escola como 
um espaço vivo que a cada dia apresenta situações novas e necessidades diversas e que engloba os processos educativos, formativos, administrativos, relacionais.

Para tanto, o papel da gestão escolar requer considerar as dez competências gerais estabelecidas na Base Nacional Comum Curricular que ressaltam aspectos, tais como: conhecimento, pensamento crítico e científico, repertório cultural, comunicação, cultura digital, trabalho e projeto de vida, argumentação, autoconhecimento e autocuidado, empatia e cooperação, responsabilidade e cidadania (BRASIL, 2017).

As competências precisam ser discutidas por todos os sujeitos da comunidade escolar, considerando nessa compreensão, as diferentes ideias que precisam ser respeitadas. Como se pretendeu discutir neste capítulo, o papel da gestão escolar representa aquele que está nesse espaço como líder para servir e buscar alternativas para o desenvolvimento humano com qualidade e que tenha como princípios envolver e integrar todos que pertencem à comunidade escolar, para assim, construir uma proposta pedagógica coletiva e efetiva.

\subsection{A gestão escolar em tempos de pandemia}

A função da gestão escolar durante o período de distanciamento social devido à pandemia, causada pela COVID-19, destaca-se por conduzir um trabalho pautado na construção da confiança e fortalecimento das relações pessoais. Nesse momento, torna-se mais evidente a necessidade de considerar os elementos estabelecidos nas Diretrizes Curriculares Nacionais da Educação Básica, tais como: compreensão da globalidade da pessoa; superação dos processos e procedimentos burocráticos; prática em que os sujeitos constitutivos da comunidade educacional discutam a própria prática pedagógica; construção de relações interpessoais solidárias; instauração de relações entre os estudantes, proporcionando-lhes espaços de convivência e situações de aprendizagem; presença articuladora e mobilizadora do gestor no cotidiano da instituição e nos espaços com os quais a escola interage (BRASIL, 2013, p. 57).

Apesar de o distanciamento físico, as pessoas continuam interagindo, estão presentes de forma virtual e a escola, nesse momento, assume uma relação diferente. 
Para desenvolver habilidades pautadas na valorização do ser humano, é necessário enfrentar o desafio de vivê-las no ambiente escolar, seja este físico ou virtual, nas relações existentes na escola e, assim, refletir e propor caminhos para manter as pessoas, nas suas individualidades, integradas nos objetivos e missão da escola.

Quando Libâneo (2015, p. 120) afirma que "a organização escolar democrática implica não só a participação na gestão, mas a gestão da participação", traz implícito que o gestor escolar, seja na pessoa do diretor ou do coordenador pedagógico, tem a função de mediar as propostas, o desenvolvimento do trabalho, assim como as relações humanas existentes nesse contexto. Todo esse processo tornou-se evidente neste momento em que o gestor escolar teve que organizar reuniões on-line, adaptando-se às tecnologias digitais num primeiro momento (ao mesmo tempo que precisou ensinar/orientar os professores), procurar formas de manter as famílias em contato com a escola, organizar a administração da escola. São desafios que sempre existiram, porém nesse cenário, tornaram-se mais desafiadores e evidentes.

Fortalecer as relações humanas da comunidade escolar e criar relações nas quais as pessoas se sintam acolhidas nas suas dificuldades e encorajadas para enfrentar o desconhecido é também uma importante função do gestor.

Liderança corresponde não apenas a um processo de inspiração, pela influência de um líder, mas expiração, pela atuação motivada de um sujeito que se inspira e atua em acordo com essa inspiração. Da combinação entre inspiração e expiração ter-se-ia a respiração que constitui condição fundamental de vida (LÜCK, 2014, p. 36).

Nesse sentido, esse movimento apresenta-se como uma relação de troca, de reciprocidade e requer maturidade humana para enfrentar o desafio de trazer para a escola a vivência dos valores revelados em seus documentos norteadores. A gestão escolar tem o desafio de reunir e mobilizar forças. Os objetivos educacionais demandam mobilização e gerenciamento dos talentos humanos (LÜCK, 2014).

Quando a gestão escolar compartilha sua liderança com os demais profissionais promove oportunidades para as pessoas unirem-se e perceberem que "é preciso lembrarmos que educação implica ação entre pessoas, se a concebemos em seu sentido mais completo de formação humana e não apenas como processo que conduza apenas ao domínio intelectual de conteúdos” (GATTI, 2017, p. 732). 
As dificuldades enfrentadas neste momento particular da pandemia nos mostram ainda mais que precisamos do outro para viver e nos constituirmos enquanto pessoas e que é em comunidade que a escola se mantém viva. Eis aí um desafio para a gestão: reunir talentos, propor a colaboração para esperançar, animar-se em persistir e, a cada dia, recomeçar o caminho.

\subsection{O papel da gestão na formação continuada docente}

Para compreender a concepção de formação continuada é necessário considerar que ela está presente a todo instante no trabalho docente e que "o professor se faz professor em uma instituição cultural e humana, depositária de valores e expectativas de uma determinada sociedade, compreendida em um tempo histórico" (CUNHA, 2013, p.4). No contexto atual, devido à pandemia causada pela COVID-19, os professores precisaram buscar novas formas para sua interação e formação. As descobertas decorrentes desse momento histórico podem desvendar oportunidades para o maior conhecimento e aperfeiçoamento da prática docente. Não se reserva um tempo específico e em separado para a formação, pois é durante o caminho que ela se torna real e robusta. "A formação permanente do professorado teria de facilitar a reflexão prático teórica sobre a própria prática, mediante a análise da realidade, a compreensão, a interpretação e a intervenção sobre esta" (MUÑOZ, 2012, p. 45).

O trabalho docente faz-se possível somente com a interação entre os atores da escola, com a presença do outro que provoca a reflexão sobre a prática docente, portanto, é indispensável que os professores partilhem ideias, teorias, práticas por meio do diálogo, que, também é parte fundamental para sua formação. "A metamorfose da escola acontece sempre que os professores se juntam em coletivo para pensarem o trabalho, para construírem práticas pedagógicas diferentes, para responderem aos desafios colocados pelo fim do modelo escolar" (NÓVOA, 2019, p. 11).

Ousar conhecer o desigual, o que pensa diferente é um caminho para reconstruir as concepções já tidas como normas: Novas possibilidades são necessárias à formação permanente dos professores, é preciso "fazê-la mais 
dialógica, mais participativa, mais ligada a projetos de inovação [...] mais baseada no diálogo entre iguais e também entre todos os que têm algo a dizer e a contribuir com a pessoa que aprende" (MUÑOZ, 2012, p.50).

Enfrentar os desafios postos em momentos de crise, como o que estamos vivenciando, é também uma oportunidade para inovar. O gestor escolar é quem está ao lado do professor e pode tornar concretas as possibilidades de formação continuada de forma diferente. Cabe ao gestor conquistar os professores e impulsionar o seu aprendizado e crescimento. "Ele faz parte do corpo docente e sua função principal vai se dividir entre a formação de professores e a articulação do projeto político-pedagógico" (MONTEIRO, 2012, p. 28).

As dificuldades cotidianas enfrentadas na escola são oportunidades para encontrar a resolução dos problemas. Uma relação pautada no diálogo, apoio faz com que a equipe se sinta confortável em partilhar o que sabe e o que não sabe e "para saber quais devem ser os focos do projeto de formação, é preponderante conhecer a equipe docente e observar as necessidades de aprendizagem de cada um" (MONTEIRO, 2012, p. 50).

Um trabalho realizado em equipe traz consigo uma sensação de apoio e segurança. Para vencerem condições adversas no intuito de oferecerem apoio aos seus estudantes, o gestor e os docentes precisam, antes, vivenciar entre si o que pretendem desenvolver na escola com seus alunos. "Trata-se de constituir uma comunidade de formação, na qual, coletivamente, se definam espaços de experimentação pedagógica e de novas práticas, criando assim as condições para uma verdadeira formação profissional docente" (NÓVOA, 2019, p. 14).

Por meio das habilidades e competências desenvolvidas e aprimoradas no trabalho em grupo, em comunidade, o professor tem a oportunidade de crescer e consolidar sua formação continuada, lapidando tanto as relações interpessoais quanto a ação diante do desafio de incorporar as demandas do nosso século.

\section{PROCEDIMENTOS METODOLÓGICOS}

O estudo realizado nesse estágio tratou-se de uma pesquisa de natureza aplicada, tendo em vista o objetivo de usar as informações coletadas no campo para 
refinar a prática da gestão. De acordo com Malheiros (2011, p. 31), "as pesquisas aplicadas, objetivam descobertas ou novas formas de interpretar algo para serem utilizadas imediatamente".

Ao buscar compreender a realidade escolar e os movimentos que circundam sua práxis este projeto assume abordagem qualitativa, pois tem como propósito alcançar o entendimento do sujeito (MALHEIROS, 2011, p. 32), afinal, a busca por conhecer a maneira que o gestor desempenha sua função, contemplando os diferentes aspectos que lhe são pertinentes é fundamental. Há que se levar em conta que "a pesquisa qualitativa se preocupa, portanto, com aspectos da realidade que não podem ser quantificados, centrando-se na compreensão e explicação da dinâmica das relações sociais" (GERHARDT; SILVEIRA, 2009, p. 32).

Quanto ao objetivo metodológico este estudo se classificou como exploratório realizado em campo para observar as relações estabelecidas entre gestores e demais profissionais da escola. Gerhardt e Silveira (2009, p. 35) afirmam que "este tipo de pesquisa tem como objetivo proporcionar maior familiaridade com o problema, com vistas a torná-lo mais explícito ou a construir hipóteses."

Em relação ao procedimento tratou-se de pesquisa de campo, pois foi necessário coletar dados que serão analisados e considerados para a elaboração e aplicação do plano de ação. O trabalho de campo "são as perguntas que fazemos para a realidade, a partir da teoria que apresentamos e dos tópicos de pesquisa que nos fornecerão a grade ou a perspectiva de observação e de compreensão" (MINAYO, 2009, p. 76).

O campo da pesquisa foi em uma creche da rede municipal de Brusque. Entende-se Campo de Pesquisa "o recorte espacial que diz respeito à abrangência, em termos empíricos, do recorte teórico correspondente ao objeto de investigação" (MINAYO, 2009, p. 62).

O estudo realizado contou com profissionais da Educação Infantil, tendo como sujeitos da pesquisa 4 professoras e 4 monitoras da creche que atuam com bebês e crianças bem pequenas com 6 meses a 2 anos e 8 meses de idade aproximadamente. "Os sujeitos fazem parte de uma relação de intersubjetividade, de interação social com o pesquisador" (MINAYO, 2009, p. 63). 
A coleta de dados teve como instrumento uma entrevista por meio de um questionário aberto, com três questões propondo a reflexão sobre o tema de estudo. Quanto à sua forma de organização o questionário aberto é aquele "em que o informante é convidado a falar livremente sobre um tema e as perguntas do investigador, quando são feitas, buscam dar maior profundidade às reflexões" (MINAYO, 2009, p. 64). A entrevista foi seguida por um questionário estruturado com quatro questões fechadas, realizado no Google forms e aplicado via Google Drive. Quanto à sua forma de organização o questionário estruturado é aquele "no qual a escolha do informante está condicionada a dar respostas a perguntas formuladas pelo investigador" (MINAYO, 2009, p. 64).

\subsection{Plano de ação}

O Plano de Ação foi realizado na Gestão do Centro de Educação Infantil, tendo como proposta promover a formação docente continuada. Pensar um planejamento nesse sentido requer a reflexão sobre ações que possibilitem o senso de pertencimento dos profissionais ao grupo de professores e à própria instituição, pois "a importância de desenvolver uma missão comum, um senso de objetivo e localidades de atividade compartilhada entre os muitos atores envolvidos na formação de professores é um tema central" (DARLING-HAMMOND; BRANSFORD, 2019, p. $387)$.

O objetivo foi criar momentos de estudo para oportunizar a pesquisa científica, a partilha de ideias e informações, o trabalho em grupo, a autoestima dos profissionais, a autonomia para a pesquisa, o estudo e a reflexão sobre o desenvolvimento infantil e a relação com a apego, a socialização sobre a prática docente para que os docentes exercitem e desenvolvam sua autoformação. A reflexão prático teórica sobre a própria prática e a capacidade de produção de conhecimento dos professores são beneficiados pela comunicação entre os professores, a troca de experiências entre profissionais, comunidade escolar e a formação continuada (MUÑOZ, 2012). 
Importante salientar que os professores precisam enfrentar o desafio de integrar o conhecimento teórico às experiências cotidianas e dinâmicas da escola para criar uma cultura de formação contínua.

Reitera-se que esta pesquisa ocorreu de forma atípica devido à pandemia causada pela COVID-19. A fim de preservar a saúde de todos e contribuir para a prevenção da contaminação foi necessário que a comunidade escolar se afastasse por um tempo, por meio do distanciamento social, estabelecido pelas autoridades governamentais e de saúde, e da Organização Mundial da Saúde (OMS). Assim sendo, nos adaptamos a outras formas de estarmos juntos e desenvolvermos atividades para colaborar na gestão da escola.

Todas as etapas do trabalho foram desenvolvidas em take-home (videoconferência), via Google Meet e WhatsApp, também por meio de vídeo que mostrava o espaço físico e o corpo docente da escola.

Após a primeira etapa, conhecer a escola e as funções da gestão pelo Meet, foi realizada uma conversa com a gestora, via WhatsApp, para a definição do tema de interesse, que foi a formação continuada de professores. Esta etapa seguiu-se da elaboração do plano de ação que foi enviado, via Whats App, à gestora e coordenadora pedagógica. Após a devolutiva positiva da gestão, foi organizado um grupo de estudos, via WhatsApp, com as professoras, monitoras, diretora e coordenadora pedagógica para o andamento do projeto.

Na primeira semana foi realizada a postagem do plano de ação e de um vídeo elaborado pela pesquisadora com a apresentação e explicação do projeto, um roteiro para a elaboração do registro escrito no diário de bordo, seguido de uma mensagem de incentivo do educador Nélio Sprea. No final da mesma semana foi enviado o material para a realização do estudo: O capítulo "Apego" (p. 93 a 100), do livro O cuidado com bebês e crianças pequenas na creche, de Janet Gonzalez-Mena e Dianne Widmeyer Eyer (2014), utilizando o Google Drive e um vídeo produzido também pela pesquisadora com o tema "Apego e sua relação com o desenvolvimento cerebral saudável do bebê". Para a elaboração do vídeo, além de o texto já citado, foram utilizadas outras fontes para a produção do material: um capítulo do livro Neurociência e Educação, de Ramon M. Cosenza e Leonor B. Guerra (2011) e o 
episódio Arquitetura do cérebro - Conexões Cerebrais, do documentário O começo da vida, direção de Estela Renner (2016). Em seguida da devolutiva das profissionais, foi enviado um questionário sobre a formação, realizado no Google Forms e disponibilizado via Google Drive. O desenvolvimento desse trabalho, em todas as suas etapas, culminou para a última, a elaboração de um portfólio que documenta o estudo.

O meio de interação utilizado foi o WhatsApp, no qual, além do envio dos materiais, foram realizadas as interações entre a pesquisadora, as professoras e monitoras: esclarecimentos sobre o roteiro de estudos, definição de datas para entrega dos registros, devolutiva sobre os estudos realizados, mensagens de agradecimento e de parabéns pelo dia dos professores, mensagens enviadas pelas profissionais, postagem de questionário.

Foi necessário refletir sobre um plano para atender aos professores no momento da pandemia, como um meio de viabilizar a formação docente diante desse cenário inusitado, causado pela COVID-19 e que tornasse possível a reflexão sobre o contexto escolar, temas pertinentes à Educação Infantil e aos documentos norteadores desta etapa da Educação Básica. A Base Nacional Comum Curricular (2017) vincula o educar e cuidar, apontando o cuidado como algo indissociável do processo educativo, confere intencionalidade educativa às práticas pedagógicas na Educação Infantil e declara que na "na Educação Infantil, as aprendizagens e o desenvolvimento das crianças têm como eixos estruturantes as interações e a brincadeira, assegurando-Ihes os direitos de conviver, brincar, participar, explorar, expressar-se e conhecer-se" (BRASIL, 2017, p. 40).

O mesmo documento também certifica que as creches e pré-escolas têm o objetivo de atuar de forma complementar à família ampliando as experiências, além de diversificar e fortalecer aprendizagens "especialmente quando se trata da educação dos bebês e das crianças bem pequenas, que envolve aprendizagens muito próximas aos dois contextos (familiar e escolar), como a socialização, a autonomia e a comunicação" (BRASIL, 2017, p. 36).

A formação docente implica compreender a Educação Infantil, primeira etapa da Educação Básica, como o início e fundamento do processo educacional que deve 
contemplar a criança como um sujeito histórico portador de direitos e que produz cultura, buscando promover a sua educação integral e considerando seus aspectos cognitivos, emocionais e psicológicos.

A seguir, segue o Plano de Ação, o projeto de formação, aplicado no Estágio de Gestão composto por três etapas: estudo individual; registro escrito e socialização sobre a compreensão do tema estudado e da sua aplicação à prática docente. Ressalta-se que a proposta é uma sugestão para aprimorar a formação continuada docente e fomentar a autoformação dos professores no momento atual e futuro, quando do retorno às aulas presenciais

\subsection{Plano de Ação: Projeto de Formação Continuada}

\begin{tabular}{|c|c|c|c|c|}
\hline $\begin{array}{c}\text { Proposta De } \\
\text { Formação }\end{array}$ & $\begin{array}{c}\text { Título Texto } \\
\text { / Vídeo }\end{array}$ & Referência & $\begin{array}{l}\text { Meio de } \\
\text { Interacão }\end{array}$ & $\begin{array}{l}\text { Tempo de } \\
\text { Execucão }\end{array}$ \\
\hline $\begin{array}{l}\text { Reflexão sobre a } \\
\text { importância da } \\
\text { autorformação } \\
\text { docente. } \\
\text { Organização do } \\
\text { tempo de estudo e } \\
\text { material }\end{array}$ & $\begin{array}{l}\text { Vídeo } \\
\text { produzido } \\
\text { pela } \\
\text { acadêmica } \\
\text { com a } \\
\text { apresentação } \\
\text { da proposta }\end{array}$ & & WhatsApp & 1 semana \\
\hline $\begin{array}{ll}\checkmark & \text { Estudo / leitura } \\
& \text { individual } \\
\checkmark & \text { Registro } \\
\checkmark & \text { Socialização }\end{array}$ & Apego & $\begin{array}{l}\text { GONZALEZ } \\
\text { MENA, Janet; } \\
\text { EYER, Dianne } \\
\text { Widmeyer. } \quad \text { o } \\
\text { cuidado com } \\
\text { bebês e crianças } \\
\text { pequenas na } \\
\text { creche. Porto } \\
\text { Alegre: AMGH, } \\
2014 .\end{array}$ & WhatsApp & 1 semana \\
\hline
\end{tabular}


Primeira Etapa: Estudo individual. Consiste na leitura e estudo de algum texto e/ou vídeo cujo tema seja pertinente à Educação Infantil. O plano propõe um tema específico para o estudo alinhado à especificidade da creche, dos bebês (zero a 1 ano e 6 meses) e das crianças bem pequenas ( 1 ano e 7 meses a 3 anos e 11 meses), entretanto, o projeto incentiva a autonomia para pesquisa de temas pertinentes a esta etapa da educação e ao contexto da escola em momentos posteriores.

Segunda Etapa: Registro. Sugere-se a utilização de um diário de bordo (pode ser realizado num caderno ou arquivo no computador) no qual os profissionais farão apontamentos sobre o que foi estudado. O registro é de caráter pessoal, não há certo ou errado, o que importa é o registro do que foi mais significativo para o docente durante a leitura / estudo. Segue um roteiro para contribuir com as reflexões pessoais a serem registradas no diário de bordo:

\begin{tabular}{|l|}
\hline \multicolumn{1}{|c|}{ ROTEIRO PARA REGISTRO NO DIÁRIO DE BORDO: } \\
\hline Data: \\
\hline Título do texto: \\
\hline $\begin{array}{l}\text { Informações relevantes: (fazer apontamentos de informações que você } \\
\text { considera mais importantes: dados, curiosidades, frases, dentre outros). }\end{array}$ \\
\hline $\begin{array}{l}\text { Aprendizado deste texto e/ou vídeo para mim hoje: (registrar, de forma geral e } \\
\text { com suas palavras, qual a mensagem do texto para você neste momento atual. } \\
\text { Importante: não há certo ou errado, o que importa é a sua reflexão). }\end{array}$ \\
\hline $\begin{array}{l}\text { Como posso aplicar o que estudei na minha prática docente? (Considerando } \\
\text { o contexto da sua escola e as crianças da sua turma, como você poderia aplicar a } \\
\text { teoria estudada à sua prática). }\end{array}$ \\
\hline Referências:
\end{tabular}

Terceira Etapa: Socialização. Após o estudo pessoal e apontamentos no diário de bordo, sugere-se realizar a partilha do que foi registrado com as demais professoras e monitoras. A profissional poderá fotografar ou enviar o arquivo do seu registro no grupo de estudos a fim de que possa socializar sua reflexão e conhecer opiniões diversas da sua com o intuito de ampliar o conhecimento teórico e aprimorar a prática docente de todos no grupo. Para isso, propõe-se formar grupos de estudos 
virtuais e presenciais quando possível. A partilha das reflexões, neste momento, será realizada no grupo de estudos, tendo como meio de interação o WhatsApp.

Sugestão para meio de interação em momentos futuros:

- criar um Blog da Escola para o registro dessas partilhas (durante a pandemia e/ou no retorno às atividades presenciais);

- encontros presenciais em momentos planejados pela gestão e corpo docente (no momento do retorno às atividades presenciais).

\section{ANÁLISE DOS RESULTADOS}

O plano de ação teve como proposta um roteiro que auxiliou as profissionais na leitura e no estudo de um tema relevante para a Educação Infantil, especialmente para o contexto da creche, dos bebês (zero a 1 ano e 6 meses) e das crianças bem pequenas ( 1 ano e 7 meses a 3 anos e 11 meses). O projeto apresentado foi além da leitura, buscou aprofundar a reflexão sugerindo pensar na aplicação do conteúdo estudado ao cotidiano escolar e à prática docente. Esse processo foi arrematado com o registro escrito de um diário de bordo, etapa importante, pois a escrita é um instrumento relevante de reflexão para a prática docente. O processo de escrita requer uma elaboração de ideias, sentimentos, retomada de lembranças significativas e que podem ser ressignificadas, o que numa escrita sobre a prática pedagógica se torna relevante para o desdobrar de novas práticas e "constituem-se pela expressão e pela elaboração do pensamento e dos dilemas dos docentes. Desse modo, aqueles que escrevem diários podem tornar-se investigadores de si próprios e, consequentemente, da prática que desenvolvem na escola" (SOUZA et al., 2012, p. 185).

$O$ ato de escrever demanda pensar e refletir sobre nós mesmos, fato fundamental para o professor, especialmente o profissional que trabalha com os bebês. A atuação docente neste contexto de creche requer um olhar cuidadoso às suas práticas cotidianas, às rotinas, ao ambiente, aos gestos, atitudes e as suas concepções do educador. Sabemos que as interações promovem efeitos em ambos em que elas se estabelecem, educador e educando, neste caso, os bebês e as crianças bem pequenas, e ainda, não qualquer interação que falamos, mas a que tem como base o respeito e a reciprocidade. 
Relações entre cuidadores e crianças muito pequenas não acontecem por acaso. Elas se desenvolvem a partir de uma série de interações. Logo, interação, isto é, o efeito que uma pessoa tem sobre outra, é também uma expressão-chave. Mas as relações não se desenvolvem a partir de qualquer tipo de interação; elas se desenvolvem a partir daquelas que são respeitosas, positivamente reativas e recíprocas (GONZALEZ - MENA; EYER, 2014, p. 4).

Para desempenhar seu papel o professor precisa aprofundar seu conhecimento por meio do estudo de temas específicos para o público que atende. A escolha do tema "Apego", conforme referência citada no projeto, aborda-o como um processo contínuo e complexo que envolve proximidade, vínculo e reatividade, positiva a uma criança, ou seja, uma resposta atenciosa à ação da criança. Também explica como o desenvolvimento cerebral é influenciado pelas primeiras experiências na infância e como as crianças dependem de relações positivas para tornarem-se seguras e autoconfiantes. "Estudos sobre o cérebro confirmam que interações calorosas e positivas estabilizam as conexões cerebrais. Devem ser prestados cuidados positivamente reativos e de alta qualidade para que esse processo apego prospere" (GONZALEZ-MENA; EYER, 2014, p. 96).

Conhecer mais profundamente esse processo e as implicações das atitudes e escolhas do educador para promover situações e relações estáveis é fundamental para uma prática docente coerente e para o desenvolvimento dos bebês e das crianças bem pequenas.

Atualmente os estudos de desenvolvimento cerebral indicam que tais
primeiras experiências, se repetidas, de fato formam padrões neurais
estáveis. O jeito que pensamos e aprendemos tem tudo a ver com a extensão
e a natureza desses padrões. Quando uma criança muito pequena
experimenta uma novidade, ou um problema, a atividade cerebral aumenta e
os padrões neurais se desenvolvem. Se os padrões neurais forem sólidos, os
sinais viajarão rápido e a criança conseguirá resolver os problemas com
facilidade (GONZALEZ-MENA; EYER, 2014, p. 95).

Além de o estudo e reflexão individual, a troca de ideias e a partilha de conhecimentos e experiências é algo intrínseco ao trabalho do professor. A prática da socialização em momentos de estudos em grupo é basilar para a construção de uma equipe que busca um objetivo em comum. Dentro dessa concepção "comunidades de prática desempenham um papel central no desenvolvimento e na transmissão do conhecimento da prática para a pesquisa, e vice-versa" (DARLING-HAMMOND; BRANSFORD, 2019, p. 327). 
O grupo de estudos foi realizado com 8 profissionais, porém contou com a participação de 7 (4 professoras e 3 monitoras), uma das profissionais, mesmo com o contato privado e disponibilização de auxílio, feitos pela pesquisadora, preferiu não participar. Ao analisar as devolutivas fica evidente a compreensão por parte das docentes e monitoras sobre o tema estudado e sobre sua pertinência à faixa etária específica dos bebês e das crianças bem pequenas. Os trechos a seguir testemunham esse processo de reflexão:

\begin{abstract}
Nesse sentido, é necessário que os profissionais de educação que interagem com crianças estabeleçam relações com apego positivo e constante para contribuir para a formação de indivíduos autônomos, confiantes capazes de atuar na sociedade de forma plena [...] O estudo proporcionou uma reflexão profunda acerca do tema, contribuindo pra aquisição de novos saberes e para a evolução pedagógica valorosa. (Educadora 1, Diário de Bordo)
\end{abstract}

$\mathrm{Na}$ atualidade as famílias estão cada dia deixando seus bebês mais cedo na escola, com isso, o profissional da educação torna-se fundamental neste processo, sendo um parceiro da família [...] A temática foi relevante trazendo informações e questionamentos que foram muito válidos para minha formação (Educadora 2, Diário de Bordo).

Estando sob os cuidados da monitora ou da professora e longe dos pais, devemos lembrar que é em nós que eles buscam proximidade e comunicam seus sentimentos de estresse e aflição (Educadora 3, Diário de Bordo).

Levando para dentro da creche, da nossa turma um olhar mais cuidadoso em relação aos sentimentos e necessidades dos nossos bebês, criando com eles laços que vão levar para a vida dele [...] O estudo contribuiu para minha formação onde buscarei a valorizar ainda mais os laços que criamos com nossos bebês, trazendo ainda mais seguranças a eles (Educadora 4, Diário de Bordo)

Sem dúvidas, refletindo sobre a prática pedagógica e na construção de novos saberes. Ao planejar colocar apego consciente, positivo e de qualidade em todas as atividades aplicadas. Em todas as fases da vida o apego se faz necessário, no entanto é na primeira infância que se consolidam fatores que serão relevantes durante toda existência (Educadora 5, Diário de Bordo).

É através de uma relação afetiva acolhedora que a criança se sente segura. Tendo conhecimento da importância e comprometimento com meus alunos levarei para minha prática docente um olhar mais criterioso em relação ao apego e sua importância no desenvolvimento da criança (Educadora 6, Diário de Bordo).

$\mathrm{O}$ afeto impulsiona a criança a construir significados importantes na sua aprendizagem, e para que isto aconteça, é necessário existir um bom relacionamento entre professor e a criança. Com as reflexões a cerca deste importante tema, buscarei valorizar ainda mais a relação afetiva entre professor e aluno, promovendo uma educação de qualidade para o desenvolvimento integral da criança (Educadora 7, Diário de Bordo).

$\mathrm{Na}$ questão em que se solicitou pensar sobre como aplicar a teoria estudada à prática docente, as profissionais também discorreram sobre a importância de proporcionar experiências positivas, ter um olhar criterioso em relação ao apego, 
valorizar a relação afetiva entre professor e aluno, refletir sobre a prática pedagógica, ter atenção ao ambiente, por exemplo, aos sons, tom de voz da profissional, atentarse para o fato de os bebês frequentam a creche cada vez mais cedo, dentre outros aspectos ligados à importância das primeiras experiências no desenvolvimento das crianças.

As devolutivas foram partilhadas no grupo de estudos com a intenção de fomentar o conhecimento e motivar a troca de saberes entre as profissionais. $O$ fato de um profissional optar por não participar do grupo de estudos também aponta um dado para análise, afinal, as pessoas são diferentes e diversas na sua forma de expressar e relacionar, sendo assim, a ausência também poderia ter ocorrido num contexto de reunião presencial e pede um olhar atento e respeitoso ao tempo de cada profissional pela gestão escolar que gerencia a formação docente também. Nem todos os profissionais estão preparados para a reflexão, um olhar sobre seu trabalho e possíveis mudanças, mas que se faz necessário, e essa omissão preocupa, pois deve ser uma tarefa cotidiana e permanente a formação, espontânea, diga-se, até natural, pois já faz parte dos saberes docentes contemporâneos e constitui a identidade do educador deste século. Ressaltamos na análise que, a lacuna deixada pela presença física não dificultou esse processo de formação docente, mas ampliou o olhar para futuras possibilidades.

Após a postagem dos registros foi encaminhada uma devolutiva, parabenizando e apontando alguns aspectos citados pelas profissionais. Em seguida, foi proposto um questionário, realizado no Google Forms e aplicado via Google Drive, para recolher informações sobre a formação realizada para reflexão também da pesquisadora sobre sua prática.

Conforme o resumo das respostas, 6 das 7 profissionais entrevistadas responderam às questões propostas. Dentre elas, $50 \%$ das profissionais responderam que atuam há mais de 10 anos na Educação; $50 \%$ dividiram suas respostas em até um ano e entre 5 e 10 anos. Todas as profissionais responderam que já participaram de outros grupos de estudo.

Ao serem questionadas sobre qual a etapa mais desafiadora na realização do estudo, as respostas foram variadas, tendo maior predominância no aspecto do 
registro escrito em relação à compreensão do texto estudado, em $50 \%$ das participantes da pesquisa, índice expressivo. Essa dificuldade de registro para os educadores nos traz uma reflexão preocupante, pois a ferramenta mais utilizada por esse profissional deve ser a linguagem escrita também, além de a oral.

Essa prática se torna cada vez mais relevante na atuação docente, pois implica conhecimento, compreensão, aplicação, análise, síntese e avaliação, categorias mentais, que, segundo os estudos de Bloom, estudioso norte-americano, ocorridos em 1973, citados por Monteiro, Teixeira e Porto (2012), são objetivos cognitivos que fazem parte de um processo de aprendizagem significativo, categorizados em graus de menor para maior complexidade.

Os objetivos educacionais focam a aprendizagem de conhecimentos, desde a recordação e compreensão de algo estudado até a capacidade de aplicar, analisar e reorganizar a aprendizagem de um modo singular e criativo, reordenando o material ou combinando-o com ideias ou métodos anteriormente aprendidos (MONTEIRO; TEIXEIRA; PORTO, 2012, p. 3).

O questionamento sobre a possibilidade de participar de grupos de estudo na escola teve resposta unânime: $100 \%$ das profissionais entendem a importância do trabalho em grupo. O confronto das devolutivas do estudo e respostas do questionário assinala que fatores, tais como: o tempo de atuação e desafios não são fatores impeditivos para a disponibilidade dos professores em trabalhar em comunidade, além de apontarem essa prática como uma oportunidade para desenvolvimento e aperfeiçoamento da prática.

[...] Ao trabalharem juntos em comunidade, tanto os professores novos quanto os mais experientes apresentam problemas, identificam discrepâncias entre teoria e prática, desafiam rotinas comuns, recorrem ao trabalho de outros para estruturas geradoras e tentam tornar evidente muito daquilo que é dado como certo sobre ensino e aprendizagem (COCHRAN-SMITH; LYTLE, 1999 apud DARLING-HAMMOND; BRANSFORD, 2019, p 327).

Os educadores, portanto, são membros de um grupo profissional que partilha desenvolvimento, vislumbram e apropriam-se da identidade de eternos aprendizes para continuarem a ser, a cada dia, a cada situação, melhores professores. 


\section{CONSIDERAÇÕES FINAIS}

O presente estudo foi delineado buscando compreender o papel do professor, neste caso, especificamente o educador de bebês e de crianças bem pequenas, assim como a construção da sua identidade profissional com a especificidade da sua atuação educativa e a relevância da gestão escolar na formação continuada desses profissionais, inclusive em tempos de distanciamento físico decorrente da pandemia causada pela COVID-19.

A educação na creche também é um direito da criança e não devemos concebêla ao assistencialismo, sendo necessário refletir sobre as ações e a oferta de um espaço de desenvolvimento do bebê e da criança bem pequena, em que o cuidar e o educar são processos indissociáveis e a escuta, que vai além de enxergar o visível, faz-se presente "Escutar com o coração requer, sobretudo, afeto para com quem estamos falando, tempo e todo o nosso desejo de entender, é por isso que a escola da infância é o lugar ideal para iniciá-los nessa atitude" (BARDANCA; BARDANCA, 2018, p. 113).

A escola é o espaço onde, na medida em que os bebês convivem com outros bebês, crianças e adultos, aprendem sobre as relações, as brincadeiras e interações que são fundamentais para seu desenvolvimento. Nesse contexto, é importante fortalecer os vínculos e investir no clima afetivo, com relações de interesse genuíno pela criança, possibilitando perceber as reações, características, necessidades, também suas superações, mas consciente de que o professor tem um papel distinto da família. "O apego aos cuidadores é diferente do apego aos pais de muitas formas. Uma delas é obviamente relativa à duração da relação. $O$ apego aos pais dura uma vida toda, já os cuidadores dispõem de um período bem mais curto" (GONZALEZ MENA; EYER, 2014, p. 96).

O estudo promoveu a reflexão sobre o fundamental papel do educador de bebês e de crianças bem pequenas, que não é substituto da mãe, da família, mas é o adulto de referência para a criança no espaço escolar. $O$ educador é a pessoa responsável por acolher, é o adulto que terá uma relação de afeto com a criança, alguém que possibilita que ela se sinta mais segura, num clima de afetividade, base para o desenvolvimento e a aprendizagem integral. 
Todo esse processo precisa estar permeado pelas teorias, e as relações não podem ser improvisadas, mas com intencionalidade educativa, pensadas para promover o desenvolvimento saudável e na sua integralidade. "Cuidadores também devem ser humanos e sair de seu papel tradicional às vezes, para interagir de modo mais intenso e passional com as crianças; mas, mais do que isso, eles precisam ser bastante objetivos e reflexivos quanto aos próprios objetivos e reações" (GONZALEZ - MENA; EYER, 2014, p. 310).

Cabe destacar que os professores devem estar pautados em objetivos de aprendizagem, concebidos como diagnósticos do processo de cada criança, refletidos nos comportamentos dela, na ideia de que toda aprendizagem mobiliza, altera esse processo e, assim, possam repensá-los para atender às individualidades, bem como para refletirem sobre sua própria prática pedagógica, que elevada à reflexão-ação e reflexão-ação-reflexão, denomina-se de práxis.

As práticas pedagógicas são vivas, existenciais por natureza, interativas e
impactantes. As práticas pedagógicas são aquelas práticas que se organizam
para concretizar determinadas expectativas educacionais. São práticas
carregadas de intencionalidade e isso ocorre porque o próprio sentido de
práxis configura-se através do estabelecimento de uma intencionalidade,
que dirige e dá sentido à ação, solicitando uma intervenção planejada e
científica sobre o objeto, com vistas à transformação da realidade social
(FRANCO, 2015, p. 604 , grifo nosso).

A intencionalidade no processo educativo, no entanto, deve ultrapassar 0 conhecimento técnico e desenvolver um olhar sobre si e sobre o outro, do cuidar, do estar junto, de entender aquilo que, neste caso da pesquisa, a criança fala, apresenta, como se comporta, e também o que ela não fala, já que a linguagem está além de a oral. Nessa perspectiva, a formação dos profissionais em harmonia com a equipe gestora requer uma ação baseada em compreender a intenção desse espaço e descobrir como o bebê e a criança pequena crescem e se desenvolvem. Esse processo passa, necessariamente por um autoconhecimento e transformação que não se restringe ao espaço, ao ambiente, mas antes pressupõe a transformação

[...] a aprendizagem ao longo da vida envolve, com frequência, inúmeras mudanças (inovações) que exigem abandonar velhas rotinas, crenças e práticas. [...] os professores que experimentam trabalhar em equipe para considerar tais questões encaram isso como papel profissional e de uma atividade importante e contínua, e não como uma ameaça ao que eles vinham fazendo anteriormente (DARLING-HAMMOND; BRANSFORD, 2019, p. 312). 
O trabalho desenvolvido no grupo de estudos confirma que quando o educador tem oportunidade e tempo dedicado a observar e compreender o desenvolvimento das crianças, ele tem a chance de transformar-se e aprimorar seu autoconhecimento. Ao observar a evolução e desenvolvimento do bebê e da criança pequena o próprio educador desenvolve-se permitindo uma mudança de consciência. No entanto, para bem observar as crianças é necessário partir de algum ponto, de alguns critérios que podem ser construídos nos momentos de formação docente.

Nesse sentido, os espaços de reflexão são fundamentais para a troca de experiências, diálogos, resoluções de problemas, estudos em equipe "[...] aplicação e inovação encontram-se estreitamente entrelaçadas e precisam ser aprendidas ao mesmo tempo, no contexto de um esquema que forneça um meio de reflexão e aprendizagem contínuas" (DARLING-HAMMOND; BRANSFORD, 2019, p. 320).

Pautado em conhecimento teórico o professor tem condições de orientar a sua prática docente para observar o bebê e a criança bem pequena, o contexto da escola e refletir sobre suas ações. As estratégias sugeridas pela pesquisadora, por exemplo, o registro escrito, auxiliaram este processo e aprimoram a reflexão. O apontamento, feito pelas profissionais, do registro escrito como a etapa mais desafiadora revela que essa prática requer maior reflexão do profissional.

O registo escrito, tanto das vivências pessoais como das práticas profissionais, é essencial para que cada um adquira uma maior consciência do seu trabalho e da sua identidade como professor. A formação deve contribuir para criar nos futuros professores hábitos de reflexão e de autorreflexão (NÓVOA, 2009, p. 26).

Oportunizar momentos de reflexão e desenvolvimento pessoal é necessário para consolidar o desenvolvimento profissional. E nesse sentido, o professor precisa sentir-se apoiado pela gestão, da mesma forma, o gestor escolar, precisa estar alinhado e seguro para abrir o espaço às novas práticas. É vital estabelecer uma relação de confiança que se dá nos detalhes, na maneira de receber e abordar as pessoas, no cuidado com o ambiente, no respeito à individualidade do educador.

O fato de a ausência de uma profissional no estudo proposto também requer o acolhimento, respeito e a reflexão sobre estratégias diversas para engajá-la no objetivo maior da escola. Ao acolher a decisão dos profissionais, o gestor tem a 
chance de abrir portas para aprimorar-se para buscar outras estratégias e reconhecer que as pessoas agem de maneiras diversas.

O mesmo clima de afeto e acolhimento, que se quer para a os bebês e as crianças bem pequenas, precisa ser concebido entre a equipe, pois são profissionais que, cada qual com seu papel, sua singularidade, estão juntos em prol de algo muito maior, da educação como ato de transformação de todos os envolvidos, neste caso, do professor, que, antes de ser este profissional é um ser humano, uma pessoaprofessor-pessoa. "Ora esta relação (a qualidade desta relação) exige que os professores sejam pessoas inteiras [...] Trata-se, sim, de reconhecer que a necessária tecnicidade e cientificidade do trabalho docente não esgotam todo o ser professor" (NÓVOA, 2009, p. 26).

Nesse contexto, o papel do gestor educacional é essencial, para oferecer os cuidados para que o professor e os demais profissionais se sintam confiantes, acolhidos em suas singularidades, com espaço para o diálogo e a participação, com projeto de formação permanente, aberto para a resolução das dificuldades do cotidiano, e para o desenvolvimento de habilidades em consonância aos valores da escola e aos princípios da proposta pedagógica, como a solidariedade, a empatia, a cooperação. A gestão e os professores são os agentes no espaço educativo, considerando as ações também vinculadas aos conhecimentos da docência. "Escolas são o território e os professores são os agentes desse processo, lembrando que gestores escolares são formados inicialmente como professores e, em seu trabalho, o domínio dos conhecimentos sobre a função de ensinar do educando é essencial" (GATTI, 2017, p. 734).

Por outro lado, o gestor precisa estar atento ao contexto da escola, dificuldades dos professores e apontar caminhos, direcionar temas para estudo, oportunizar ferramentas e tempo para a reflexão sobre a prática docente e promover a formação de um educador consciente das suas possibilidades e capaz de aprender com o outro, sabendo que ninguém é completo em se tratando de formação docente.

O trabalho entre a gestão ou a equipe gestora com os professores precisa estar centrado na parceria e não no autoritarismo, contemplando um espaço constante de reflexão, tanto do campo da teoria quanto das práticas pedagógicas, e nessa 
comunidade colaborativa cria-se uma identidade docente, um sentimento de pertencer, resultando dessa forma uma mudança concreta das práticas docentes. "Através dos movimentos pedagógicos ou das comunidades de prática, reforça-se um sentimento de pertença e de identidade profissional que é essencial para que os professores se apropriem dos processos de mudança e os transformem em práticas concretas de intervenção" (NÓVOA, 2009, p. 27).

Nesse sentido, a gestão precisa envolver-se nas rotinas para constituir e guiar caminhos para novos olhares, além de momentos destinados à leitura, estudos, pesquisas, reflexão e partilha entre a equipe. Este é um caminho para compreender que nem tudo precisa ser mudado, mas há coisas que podem ser adaptadas, redirecionadas e que a mudança é um processo que se fortalece nas situações diárias e na coletividade. O olhar para si, para as práticas, ocorre muitas vezes, a partir do feedback de outros, concebido aqui como dos próprios pares, dos autores, dos alunos, até das famílias, o que faz o movimento permanente da aprendizagem docente, base para melhores tomadas de decisão em relação ao itinerário formativo das crianças. "A verdadeira expertise adaptativa para um profissional de ensino envolve uma profunda avaliação do valor de buscar ativamente o feedback de diversas fontes" (DARLINGHAMMOND; BRANSFORD, 2019, p. 312).

A formação docente é uma estrada longa que oferece infinitas possibilidades e que leva a caminhos ilimitados de construções e desconstruções diárias. Ainda, cada criança que passa pela vida do professor, cada bebê, tem o poder de transformá-lo e lembrá-lo de que somos inacabados e precisamos, tal qual essas pessoas o fazem, estar dispostos e disponíveis com uma mente aberta e curiosa, para uma constante e contínua formação.

\section{REFERÊNCIAS}

BARDANCA, Angeles Abelleira; BARDANCA, Isabel Abelleira. Os fios da Infância. São Paulo: Phorte, 2018.

BRASIL. Ministério da Educação. Base Nacional Comum Curricular: educação é a base. Brasília: MEC, 2017. Disponível em:

http://basenacionalcomum.mec.gov.br/images/BNCC_El_EF_110518_versaofinal_sit e.pdf. Acesso em: 28 ago. 2020. 
BRASIL. Constituição (1988). Constituição da República Federativa do Brasil: promulgada em 5 de outubro de 1988. Disponível em: http://www.planalto.gov.br/ccivil_03/constituicao/constituicao.htm. Acesso em: 10 ago. 2020.

BRASIL. Diretrizes Curriculares Nacionais da Educação Básica. Brasília, 2013. Disponível em:

http://portal.mec.gov.br/index.php?option=com_docman\&view=download\&alias=1344 8-diretrizes-curiculares-nacionais-2013-pdf\&ltemid=30192. Acesso em: $1^{\circ}$ set. 2020.

BRASIL. Lei de Diretrizes e Bases da Educação. Lei n 9.394. 1996. Disponível em: http://www.planalto.gov.br/ccivil_03/leis/19394.htm. Acesso em: 16 ago. 2020.

COSENZA, R. M.; GUERRA, L. B. Neurociência e educação. Porto Alegre: Artmed, 2011.

CUNHA, Maria Isabel da. O tema da formação de professores: trajetórias e tendências do campo na pesquisa e na ação. Educação e Pesquisa, vol.39, n.3, 2013. Disponível em: https://www.scielo.br/pdf/ep/v39n3/aop1096. pdf. Acesso em: 02 set. 2020.

DARLING-HAMMOND, Linda; BRANSFORD, John. Preparando os professores para um mundo em transformação. Porto Alegre: Penso, 2019.

FRANCO, M. A. S. Práticas Pedagógicas de ensinar-aprender: Poe entre resistências e resignações. Educ. Pesqui. São Paulo, v. 41, n.3, p. 601-614, jul/set 2015. Disponível em:

https://www.periodicos.ufam.edu.br/index.php/rech/article/view/5146. Acesso em: 2 nov. 2020.

GATTI, Bernardete Angelina. Formação de professores, complexidade e trabalho docente. Revista Diálogo Educacional, Curitiba, v. 17, n. 53, p. 721-737, 2017. Disponível em:

https://periodicos.pucpr.br/index.php/dialogoeducacional/article/viewFile/8429/17739. Acesso em: 12 set. 2020.

GERHARDT, Tatiana Engel; SILVEIRA, Denise Tolfo, (org). Métodos de pesquisa. Porto Alegre: Editora da UFRGS, 2009. Disponível em:

http://www.ufrgs.br/cursopgdr/downloadsSerie/derad005.pdf. Acesso em: 08 ago. 2020.

GONZALEZ - MENA, Janet; EYER, Dianne Widmeyer. 0 cuidado com bebês e crianças pequenas na creche. Porto Alegre: AMGH, 2014.

LIBÂNEO, José Carlos. Educação escolar: políticas, estrutura e organização. 10. ed. São Paulo: Cortez Editora, 2012. 
LIBÂNEO, José Carlos. Organização e gestão da escola: teoria e prática. 6. ed. rev. e ampl. São Paulo: Heccus Editora, 2015.

LÜCK, Heloísa. Dimensões de gestão escolar e suas competências. Curitiba: Editora Positivo, 2009.

LÜCK, Heloísa. A evolução da gestão educacional, a partir de mudança paradigmática. Gestão em Rede, n. 03, nov, p. 13-18, 1997.

LÜCK, Heloísa. Liderança em Gestão Escolar. Petrópolis: Vozes, 2014. Disponível em: https://plataforma.bvirtual.com.br/Leitor/Publicacao/114666/pdf/0.Acesso em: 13 ago. 2020.

MALHEIROS, Bruno Taranto. Metodologia da pesquisa em educação. Rio de Janeiro: LCT, 2011.

MINAYO, Maria Cecília de Souza. Pesquisa Social. 16. ed. Rio de Janeiro: Editora Vozes, 2009. Disponível em: http://www.mobilizadores.org.br/wpcontent/uploads/2015/03/MINAYO-M.-Cec\%C3\%ADlia-org.-Pesquisa-social-teoriam\%C3\%A9todo-e-criatividade.pdf. Acesso em: 08 mar. 2020.

MONTEIRO, Elisabete (et al). Coordenador pedagógico: função, rotina e prática.1. ed. Palmeiras: Instituto Chapada de Educação e Pesquisa, 2012. (Série educar em rede).

MONTEIRO, I. G.; TEIXEIRA, K. R de M; PORTO, R. G. Os níveis cognitivos da Taxonomia de Bloom: existe necessariamente uma subordinação hierárquica entre eles? XXXVI Encontro da ANPAD. Rio de Janeiro/ RJ. 22 a 26 de setembro de 2012. Disponível em: http://www.anpad.org.br/admin/pdf/2012_EPQ1887.pdf. Acesso em: 2 nov. 2020.

MUÑOZ, Francisco Imbernón. Formação permanente e carreira docente. [Entrevista concedida a] Edite Maria Sudbrack. Revista de Ciências Humanas, v.13, n. 20, jun. 2012. Disponível em:

http://revistas.fw.uri.br/index.php/revistadech/article/viewFile/352/637. Acesso em: 20 ago. 2020.

NÓVOA, António. Para uma formação de professores construída dentro da profissão. Revista Educacion, v.2, 2009. Disponível em:

http://www.revistaeducacion.educacion.es/re350/re350_09por.pdf. Acesso em: 04 set. 2020.

NÓVOA, Antonio. Os Professores e a sua Formação num Tempo de Metamorfose da Escola. Educação \& Realidade, Porto Alegre, vol.44 n.3 Porto Alegre, 2019. Disponível em: https://www.scielo.br/scielo.php?script=sci_arttext\&pid=S2175$62362019000300402 \&$ tlng=pt. Acesso em: 02 set. 2020

O COMEÇO DA VIDA; Direção: Estela Renner. Produção: Maria Farinha Filmes. São Paulo, 2016. 
SANDER, Benno. A pesquisa sobre política e gestão da educação no Brasil: uma leitura introdutória sobre sua construção. RBPAE, v. 23, n. 3, p. 421-447, 2007.

SILVA, Josias Benevides da. Um olhar histórico sobre a gestão escolar. Educação em Revista, Marília, v.8, n.1, p.21-34, 2007.

SOUZA, Ana Paula Gestoso de et al. A escrita de diários na formação docente. Educação em revista. Belo Horizonte, v.28, n.01, mar. 2012. p.181-210. 